\title{
Factors Associated with Practice of Health Information Protection among Nursing Students
}

\author{
Cha, Kyeongin ${ }^{1)} \cdot$ Song, Youngshin ${ }^{2)}$
}

1) Ph.D. Candidate, College of Nursing, Chungnam National University. Daejeon

2) Professor, College of Nursing, Chungnam National University, Daejeon, Korea

\begin{abstract}
Purpose: Health information protection policy has received increased emphasis in the medical environment. Nursing students are required to access personal health information in practical training to achieve the necessary credits. This study was done to identify the effects of nursing students' ethical index and their awareness of health information protection on their practice in terms of health information protection. Methods: Participants for this cross-sectional descriptive design study were 238 nursing students who had undergone clinical practice at four universities in J province. Information ethics index, awareness of health information protection, and its practice were measured using self-report questionnaires. Collected data were analyzed using descriptive statistics, Pearson correlations, and multiple regression analysis. Results: Among the participants, $88.2 \%$ were female and $55.0 \%$ identified as religious. A positive correlation was found between awareness of health information protection and the information ethics index $(r=.60, p<.01)$. In the multiple regression model, $37.4 \%$ of the variance in students' health information protection behavior was predicted by religion $(\beta=.13, p=.033)$, the respect domain of the information ethics index $(\beta=.22, p=.033)$, and awareness of health information protection $(\beta=.61, p<.001)$. Conclusion: To improve health information protection behavior in nursing students, religion, awareness of health information protection, and the respect component of the information ethical index should be considered when developing systematic education programs.
\end{abstract}

Key Words: Nursing students; Nursing education; Personal health records; Computer security; Bioethics

*This article is a revision of the first author's master's thesis from College of Nursing, Chungnam National University.

Received Sep 26, 2019 Revised Jan 31, 2020 Accepted Feb 5, 2020

Corresponding author: Song, Youngshin

College of Nursing, Chungnam National University

266 Munwha-ro, Jung-gu, Daejeon 35015, Korea

Tel: +82-42-580-8334, Fax:+82-42-580-8309, E-mail: yssong87@cnu.ac.kr 


\section{INTRODUCTION}

In recent years, healthcare institutions have taken multilateral measures to minimize leakage of health information and to protect and ensure the privacy of patients, such as by establishing guidelines for personal information protection and complying with the implementation of health information protection and security systems as part of healthcare accreditation requirements [1]. As social demand for the protection of patients' personal information increased, the General Information Protection Act was enacted in March 2011 and implemented in September 2011. In addition, the Ministry of Health and Welfare revised the personal information protection guidelines of medical institutions in 2015, establishing a personal information protection law, and emphasizing the need for appropriate processing of personal information by medical institutions [2].

In Korea, the health information of patients is not only the basic data pertaining to patient care, but also the basis for health insurance claims [3,4]. Health information can also represent basic data for nursing research and education [4]. Recently, as the use of Electronic Medical Records (EMR) has become more common in medical institutions, and the importance of information management is increasing [4], ensuring the privacy of patients' health information has become a new challenge. As access to health information has improved and become easier, the likelihood of exposure of patient personal information has increased [3].

Nursing students are exposed to various forms of patient information in order to learn patient care. As the roles and responsibilities of nurses with respect to patients health information increase, nursing students must recognize the importance of protecting their patients' personal medical information and translate this recognition into practice [4]. Therefore, they should learn the ethical responsibilities for patient confidentiality, including the Nurse Ethics Code, Nightingale Oath, Nursing Ethics Principles, and Medical Law [4].

Nursing students undergoing clinical training have been found to have a lower sense of responsibility for protecting health information compared to hospital staff, as nursing students often encounter patients' information via other medical staff, are only given such information during the training program, and are often not familiar with information security protocols [5-7]. Although it is important for nursing students to understand the importance of protecting health information, there are few studies of information ethics and its influence on health in- formation protection in the context of clinical training [4-7]. Information ethics refers to the ethical problems that occur in an information network during the entire process from information generation to destruction of information [8]. To develop appropriate information ethics, the government revised the guidelines for the information and communication technology education for elementary and junior high schools and strengthened the information-related curriculum in 2011 [8], but there is no mandatory university curriculum. However, most medical institutions manage health information through EMR, and ethical standards for information protection by hospital staff, including nurses, are required. As such, emphasis on health information ethics is needed in nursing colleges.

The information ethics index (IEI) has been developed and used to assess students' ethics related to personal information encountered in internet use or in other situations in Korean daily life, by measuring the four attributes of temperance, respect, responsibility, and participation [9]. That is, IEI assesses the ability to control one's unethical behavior (temperance); due regard for the feelings, needs and expectations of others (respect); thinking about the effect of one's actions on others (responsibility); and sharing valuable information that can be helpful to others (participation)[9]. Despite the high intensity of information ethics education in adolescence, there remain concerns that students lack awareness and consistent practice of information protection when they become adults [10]. Emphasis on ethical behavior among nursing students is particularly necessary as patients' information protection includes operating with their consent, maintaining their confidentiality, and protecting their personal privacy, trust, and autonomous decision-making, as contained in ethics guidelines [4].

Previous studies have focused on the protection of patients' health information by health care workers such as nurses, physical therapists, and physicians [11-14]. Only five studies investigated the health information practices of college students in health-related fields with a clinical practice component $[4,5,13-15]$. Those studies reported patients' awareness of personal information protection or recognition and practice [4,5,13-15]. From the findings of prior studies, it is evident that nursing students with a higher level of awareness of personal information protection can better practice information protection. Although health information protection has been emphasized as an aspect of ethics [10], few studies have assessed the link between ethical norms of information protection and protection of patients' health information in practices.

In this study, the role of the ethics index and nursing 
students' awareness of health information protection were examined to determine the current status and to provide basic data regarding factors affecting protection of patients' health information.

\section{METHODS}

\section{Study Design}

This was a correlational study that investigated the relationship between the practice of health information protection among nursing students and both the information ethics index and awareness of health information protection.

\section{Participants}

Four nursing schools in J Province were conveniencesampled, and nursing students who had completed at least one year of clinical training were enrolled in this study. The required sample size was calculated to be 160 for regression analysis using the $G^{*}$ power 3.1.5 software [17] with an effect size of 0.15 [7], statistical significance of $\alpha=.05$, power $=0.95$, and eight predictors. Data from 238 participants were analyzed; oversampling was performed to maximize variety in the ethical index among nursing students, as this was the first study to use the information ethics index with this population.

\section{Measurements}

\section{1) General characteristics}

Data related to participants' age, sex, religion, and their experience of health information protection education in nursing school and at the hospital were collected.

\section{2) Information Ethics Index(IEI)}

A structured self-report questionnaire was used to determine participants' information ethics index using the IEI scale [18]. Since there is no extant tool to measure the information ethics of nursing students, we used a tool developed to measure the information ethics of adolescents. To reduce measurement error, the original developer and nursing faculty confirmed that the IEI scale items were valid in terms of content for nursing students. The IEI is composed of four domains, containing a total of 55 items that are rated using a five-point Likert scale. Temperance is assessed via 12 items, 15 items measure respect, 16 measure responsibility, and 12 measure participation. A higher domain score indicates a more positive status. In Kim
[18], Cronbach's $\alpha$ was .91 for temperance, .92 for respect, .92 for responsibility, and .90 for participation. In the current study, Cronbach's $\alpha$ was .70 for temperance, .83 for respect, .85 for responsibility, and .77 for participation. Cronbach's $\alpha$ for the total IEI was .90 .

\section{3) Health information protection awareness}

Students' health information protection scores [19] were measured using the patients' health information protection awareness (PHIPA) scale for student nurses. This validated 23-item tool consists of nine items for communication, 11 for information management ability, and three for referrals. Items are rated using a five-point Likert scale; higher scores indicate higher levels of awareness and practice of health information protection [19]. Cronbach's $\alpha$ for all 23 items was .94, and .92 for communication, .90 for information management ability, and 80 for referrals in a prior study [19]. In the current study, Cronbach's $\alpha$ was .94 for total items, and .90, .92, and .83 for communication, information management ability, and referral, respectively.

\section{4) Health information protection practice}

According to Song et al.[19], the PHIPA scale can assess not only nursing students' awareness of patients' health information protection, but also their students' practice of such information protection, by changing each question to assess how well they are currently performing. In this study, Cronbach's $\alpha$ was .96 for the total scale, while the values for communication, information management ability, and referrals were $.94, .91$, and 93, respectively.

\section{Data Collection}

Data collection was conducted from April to June 2016. Participants were recruited from the four nursing colleges located in J province. Before starting the survey, we visited the director of each nursing school to explain the purpose of the research and the survey method, obtained their agreement to participate in the study, and then arranged the distribution schedule of the questionnaire according to the schedule of each institution. To collect the data, nursing college students who had provided written consent were required to read and respond to a questionnaire after the researcher explained the research purpose, that confidentiality and anonymity were guaranteed, and that there were no disadvantages to participating. In total, 270 questionnaires were distributed, 245 were returned, and 238 questionnaires, after excluding seven participants who provided insincere or incomplete responses, were finally analyzed, resulting in a data collection rate of $88.1 \%$. 


\section{Data Analysis}

We analyzed the mean and standard deviation of the information ethics index (temperance, respect, responsibility, participation), and awareness and practice of health information protection, using the SPSS 21.0 program. Differences in the scores of the information ethics index, awareness of health information protection, and the level of health information protection practice were examined according to the general characteristics of the participants, using t-tests and a one-way ANOVA. Pearson's correlations were obtained between participants' information ethics index, awareness, and practice of health information protection.

Finally, factors associated with the practice of health information protection were analyzed using multiple regression analysis. To detect the presence of autocorrelation in the residuals from a statistical regression analysis, the Durbin-Watson statistic was performed. If result has a value between 0 and 4 , there is no autocorrelation found in this data. In this study, the value was 1.85 . In testing for multicollinearity, the tolerance limit exceeded 0.1 , ranging from .46 .99, and the variance inflation factor did not exceed 10 (1.01 2.16), confirming no multicollinearity. To perform the multiple regression analysis, participants' general characteristics, IEI domain scores, and awareness of patients' health information protection were entered in the regression model as independent variables, while their practice of health information protection was treated as the dependent variable.

The categorical variables were processed as dummy variables (gender: $0=$ female, $1=$ male; religion: $0=$ no, $1=$ yes; education: $0=$ never received education, $1=$ received education). A significance level of 0.05 was adopted.

\section{Ethical Considerations}

This study was conducted after receiving Institutional Review Board (IRB) approval (number: No. 2-1046881-AN-01-201602-HR-008) from *- University. To collect data, research consent forms were attached to the questionnaires. Before the questionnaires were completed, participants were able to read the consent form and questionnaires to decide whether to participate. The purpose of the research agreement was to explain the purpose and contents of the study; it explained that the study was being conducted by voluntary participation, and that anonymity was guaranteed. We explained that the data collected by the questionnaire would never be used for purposes other than research. After explaining to the participant that he or she could refuse or suspend participation at any time, he or she agreed to participate by signing the consent form and responding to the questionnaire. To ensure the anonymity and confidentiality of the respondents, questionnaires were collected in sealed envelopes, and immediately taken into the custody of the researchers. Collected data were stored in a lockable cabinet.

\section{RESULTS}

\section{Participants' General Characteristics}

Participants' general characteristics are shown in Table 1. The majority were female $(88.2 \%)$, and their mean age was 22.76 years. Among the 238 participants, $55 \%$ were religious, and $91 \%$ had experienced education on patient's health information protection in their schools or hospitals.

Table 1. General Characteristics of Participants

$(N=238)$

\begin{tabular}{llcc}
\hline Variables & Categories & $\mathrm{n}(\%)$ or $\mathrm{M} \pm$ SD & Range \\
\hline Gender & Female & $210(88.2)$ & \\
& Male & $28(11.8)$ & \\
Age (year) & & $22.76 \pm 2.90$ & $21 \sim 45$ \\
& 21 & $82(34.5)$ & \\
& 22 & $81(34.0)$ & \\
Religious & $\geq 23$ & $75(31.5)$ & \\
& Yes & $131(55.0)$ & \\
HIPE in schools & Yes & $107(45.0)$ & \\
or hospital & No & $217(91.0)$ & \\
\hline
\end{tabular}

$\mathrm{HIPE}=$ health information protection education.

\section{IEI \& Health Information Protection Awareness and Practice of Participants}

The mean score on the information ethics index was 5 out of 5 points in each area. The mean scores for perception and practice of health information protection were 4.38 and 4.24 out of 5 , respectively (Table 2 ).

\section{IEI, Awareness, and Practice of Health Information Protection according to General Characteristics}

The scores for IEI and awareness and practice of health information protection according to general characteristics of participants are shown in Table 3. Among the IEI domains, the responsibility and participation domains differed by age, with the 22-year-old group showing a higher level of responsibility than the 23-years-or-older group 
$(\mathrm{F}=4.84, p=.009)$, whereas 23-years-or-older group had higher level of participation than those aged 21 group $(\mathrm{F}=4.50, p=.012)$. The scores for practice of patients' health information protection were significantly higher among nursing students who identified as religious, compared to those who did not $(\mathrm{t}=2.50, p=.013)$.

Table 2. Information Ethics Index, Awareness, and Practice of Health Information Protection

$(N=238)$

\begin{tabular}{llcc}
\hline Variables & & $\mathrm{M} \pm \mathrm{SD}$ & Range \\
\hline Information & Temperance & $3.66 \pm 0.48$ & $2.17 \sim 4.92$ \\
ethics index & Respect & $4.06 \pm 0.44$ & $2.47 \sim 5.00$ \\
& Responsibility & $4.32 \pm 0.43$ & $2.94 \sim 5.00$ \\
& Participation & $3.72 \pm 0.49$ & $2.42 \sim 5.00$ \\
Awareness of health information & $4.38 \pm 0.45$ & $2.83 \sim 5.00$ \\
protection & & \\
$\begin{array}{l}\text { Practice of health information } \\
\text { protection }\end{array}$ & $4.24 \pm 0.59$ & $2.30 \sim 5.00$ \\
\hline
\end{tabular}

\section{Correlations among Variables}

The practice of patients' health information protection was positively correlated with awareness $(\mathrm{r}=.60, p<.01)$, and the IEI domains of temperance $(\mathrm{r}=.15, p<.05)$, respect $(\mathrm{r}=.42, p<.01)$, responsibility $(\mathrm{r}=.48, p<.01)$, and participation $(\mathrm{r}=.29, p<.01$; Table 4$)$.

\section{Factors Influencing the Practice of Patients' Health Information Protection}

All independent variables, such as gender, age, religion, education, IEI, and awareness of patients' health information protection, were entered in a multiple regression model, based on extant evidence [4,19]. The model showed good fit ( $\mathrm{F}=16.71, p<.001$; Table 5$)$. When general characteristics (gender, age, religion, education), IEI, and awareness of patients' health information protection were en-

Table 3. Scores for Information Ethics Index and Awareness and Practice of Health Information Protection according to General Characteristics

$(N=238)$

\begin{tabular}{|c|c|c|c|c|c|c|c|c|c|c|c|c|c|c|}
\hline \multirow{3}{*}{ Variables } & \multirow{3}{*}{ Categories } & \multirow{3}{*}{$\mathrm{n}$} & \multicolumn{8}{|c|}{ Information ethics index } & \multicolumn{4}{|c|}{ Health information protection } \\
\hline & & & \multicolumn{2}{|c|}{ Temperance } & \multicolumn{2}{|c|}{ Respect } & \multicolumn{2}{|c|}{ Responsibility } & \multicolumn{2}{|c|}{ Participation } & \multicolumn{2}{|c|}{ Awareness } & \multicolumn{2}{|c|}{ Practice } \\
\hline & & & $\mathrm{M} \pm \mathrm{SD}$ & $\begin{array}{c}\mathrm{t} \text { or } \mathrm{F} \\
(p)\end{array}$ & $\mathrm{M} \pm \mathrm{SD}$ & $\begin{array}{c}\text { t or F } \\
(p)\end{array}$ & $\mathrm{M} \pm \mathrm{SD}$ & $\begin{array}{l}\text { tor } \mathrm{F} \\
(p)\end{array}$ & $\mathrm{M} \pm \mathrm{SD}$ & $\begin{array}{l}\mathrm{t} \text { or } \mathrm{F} \\
(p)\end{array}$ & $\mathrm{M} \pm S \mathrm{D}$ & $\begin{array}{l}\mathrm{t} \text { or } \mathrm{F} \\
(p)\end{array}$ & $\mathrm{M} \pm \mathrm{SD}$ & $\begin{array}{c}\text { t or F } \\
(p)\end{array}$ \\
\hline \multirow[t]{2}{*}{ Gender } & Male & 28 & $3.60 \pm 0.47$ & -0.74 & $4.04 \pm 0.58$ & -0.21 & $4.17 \pm 0.54$ & -1.56 & $3.79 \pm 0.55$ & 0.83 & $4.36 \pm 0.49$ & -0.34 & $4.22 \pm 0.74$ & -0.25 \\
\hline & Female & 210 & $3.67 \pm 0.48$ & $(.459)$ & $4.06 \pm 0.42$ & $(.833)$ & $4.34 \pm 0.42$ & $(.129)$ & $3.71 \pm 0.48$ & $(.406)$ & $4.39 \pm 0.45$ & $(.734)$ & $4.25 \pm 0.58$ & $(.807)$ \\
\hline \multirow[t]{3}{*}{ Age (year) } & $21^{\mathrm{a}}$ & 82 & $3.62 \pm 0.50$ & 1.02 & $4.06 \pm 0.39$ & 1.36 & $4.34 \pm 0.40$ & 4.84 & $3.64 \pm 050$ & 4.50 & $4.42 \pm 0.40$ & 1.27 & $4.22 \pm 0.58$ & 0.66 \\
\hline & $22^{\mathrm{b}}$ & 81 & $3.72 \pm 0.48$ & $(.363)$ & $4.11 \pm 0.42$ & $(.258)$ & $4.41 \pm 0.40$ & $(.009)$ & $3.68 \pm 0.46$ & $(.012)$ & $4.41 \pm 0.48$ & $(.284)$ & $4.31 \pm 0.58$ & $(.517)$ \\
\hline & $\geq 23^{\mathrm{c}}$ & 75 & $3.63 \pm 0.46$ & & $4.00 \pm 0.49$ & & $4.20 \pm 0.48$ & $\mathrm{~b}>\mathrm{c}$ & $3.86 \pm 0.49$ & $c>a$ & $4.32 \pm 0.48$ & & $4.21 \pm 0.63$ & \\
\hline \multirow[t]{2}{*}{ Religious } & Yes & 107 & $3.07 \pm 0.44$ & 1.20 & $4.10 \pm 0.45$ & 1.41 & $4.34 \pm 0.46$ & 0.65 & $3.76 \pm 0.48$ & 1.27 & $4.42 \pm 0.45$ & 1.16 & $4.35 \pm 0.54$ & 2.50 \\
\hline & No & 131 & $3.62 \pm 0.51$ & $(.229)$ & $4.02 \pm 0.43$ & $(.158)$ & $4.30 \pm 0.41$ & $(.518)$ & $3.68 \pm 0.49$ & $(.204)$ & $4.35 \pm 0.46$ & $(.248)$ & $4.15 \pm 0.63$ & $(.013)$ \\
\hline \multirow{2}{*}{$\begin{array}{l}\text { HIPE in } \\
\text { schools or } \\
\text { hospital }\end{array}$} & Yes & 217 & $3.67 \pm 0.49$ & 0.87 & $4.07 \pm 0.44$ & 0.94 & $4.33 \pm 0.43$ & 0.91 & $3.72 \pm 0.48$ & 0.29 & $4.39 \pm 0.44$ & 0.47 & $4.24 \pm 0.58$ & -0.01 \\
\hline & No & 21 & $3.57 \pm 0.37$ & $(.385)$ & $3.97 \pm 0.42$ & $(.349)$ & $4.24 \pm 0.48$ & $(.364)$ & $3.69 \pm 0.56$ & $(.776)$ & $4.33 \pm 0.60$ & $(.646)$ & $4.25 \pm 0.75$ & $(.991)$ \\
\hline
\end{tabular}

HIPE=Health information protection education.

Table 4. Correlations among Variables

$(N=238)$

\begin{tabular}{|c|c|c|c|c|c|c|}
\hline \multirow{3}{*}{ Variables } & \multirow{3}{*}{ Categories } & \multicolumn{4}{|c|}{ Information ethics index } & \multirow{2}{*}{$\begin{array}{c}\text { Health information } \\
\text { protection } \\
\text { Awareness }\end{array}$} \\
\hline & & Temperance & Respect & Responsibility & Participation & \\
\hline & & $r(p)$ & $r(p)$ & $\mathrm{r}(p)$ & $r(p)$ & $\mathrm{r}(p)$ \\
\hline \multirow{4}{*}{$\begin{array}{l}\text { Information ethics } \\
\text { index }\end{array}$} & Temperance & 1 & & & & \\
\hline & Respect & $.44^{* *}$ & 1 & & & \\
\hline & Responsibility & $.35^{* *}$ & $.63^{* *}$ & 1 & & \\
\hline & Participation & $.24^{* *}$ & $.48^{* *}$ & $.40^{* *}$ & 1 & \\
\hline \multirow{2}{*}{$\begin{array}{l}\text { Health information } \\
\text { protection }\end{array}$} & Awareness & $.20^{* *}$ & $.51^{* *}$ & $.62^{* *}$ & $.45^{* *}$ & 1 \\
\hline & Practice & $.15^{*}$ & $.42^{* *}$ & $.48^{* *}$ & $.29 * *$ & $.60^{* *}$ \\
\hline
\end{tabular}

${ }^{*} p<.05,{ }^{* *} p<.01$. 
Table 5. Factors Influencing the Practice of Protection of Health Information

\begin{tabular}{|c|c|c|c|c|}
\hline \multicolumn{2}{|l|}{ Variables } & $\beta$ & $\mathrm{t}$ & $p$ \\
\hline \multicolumn{2}{|l|}{ (Constant) } & .29 & 0.74 & .458 \\
\hline \multicolumn{2}{|l|}{$\begin{array}{l}\text { Gender } \\
\qquad(\text { male }=1, \text { female }=0)\end{array}$} & -.04 & -0.32 & .747 \\
\hline \multicolumn{2}{|l|}{ Age (year) } & .06 & 1.28 & .202 \\
\hline \multicolumn{2}{|l|}{$\begin{array}{l}\text { Religious } \\
\quad(\text { yes }=1, \text { no=0) }\end{array}$} & .13 & 2.15 & .033 \\
\hline \multicolumn{2}{|l|}{$\begin{array}{l}\text { HIPE in schools or hospital } \\
(\text { yes }=1, \text { no }=0)\end{array}$} & -.08 & -0.72 & .471 \\
\hline Information ethics index & $\begin{array}{l}\text { Temperance } \\
\text { Respect } \\
\text { Responsibility } \\
\text { Participation }\end{array}$ & $\begin{array}{r}-.06 \\
.22 \\
.16 \\
-.06\end{array}$ & $\begin{array}{l}0.43 \\
0.03 \\
0.11 \\
0.43\end{array}$ & $\begin{array}{l}.428 \\
.033 \\
.109 \\
.433\end{array}$ \\
\hline \multirow{2}{*}{\multicolumn{2}{|c|}{ Awareness of health information protection }} & .61 & 6.67 & $<.001$ \\
\hline & & \multicolumn{3}{|c|}{ Adjusted $\mathrm{R}^{2}=.37, \mathrm{~F}=16.71, p<.001$} \\
\hline
\end{tabular}

HIPE=Health information protection education.

tered as independent variables, religion $(\beta=.13, p=.033)$, the IEI domain of respect $(\beta=.22, p=.033)$, and awareness of patients' health information protection $(\beta=.61, p<.001)$ were significantly correlated with the practice of patients' health information protection. These variables explained $37.4 \%$ of the total variance in the practice of patients' health information protection.

\section{DISCUSSION}

Our findings showed that the IEI domains and awareness of patients' health information protection were associated with the practice of patients' health information protection among nursing students. As discussed previously, the IEI comprises four domains (temperance, respect, responsibility, participation); the score of the four domains were above the median. We cannot compare the results of this study to those of other studies as this is the first study to investigate IEI among nursing students. However, it is worth noting that our participants scored highest on the responsibility domain, followed by respect, temperance, and participation. Furthermore, the degree of awareness and practice of patients' health information protection was higher among nursing students than nurse professionals $[3,23]$. It is difficult to directly compare differences in the types of items due to differences in constructs, but our finding may reflect the recent strengthening of education on personal information protection in the medical environment. Despite the high score for awareness and practice of patients' health information protec- tion, scores on items related to communication with nursing staff were lower than other items. In this study, nursing students had limited opportunities for communicating with medical teams on the practice of patients' health information protection.

This study aimed to identify the factors associated with the level of practice of patients' health information protection in nursing students. Among personal factors, religion was the factor that most strongly affected nursing students' practice of health information protection in this study. Generally, religion plays an important role in the formation and maintenance of social norms and religious individuals' behaviors are often informed by the shared values and moral responsibility embedded in religious codes [22]. Lim [21] found that critical thinking and ethical decision-making were more prominent among religious than non-religious students, similar to the current study. However, in prior studies [19,20], religious individuals also had more experience with ethical conflict than those who were not religious. Although religion might be related to ethical thoughts and decision-making, further research is needed to understand how the practice of patients' information protection is linked to ethical decisionmaking, and how ethical indices can reflect an individual's ethical decision-making ability.

Since the development of security policies related to personal information protection is guided by government [2], a health information education system for healthcare professionals has been established in healthcare facilities. However, operation of the education system for students 
undergoing practical training, including nursing students, differs depending on the environment and institutional culture of the hospital $[4,19]$. In the current study, approximately $85 \%$ of participants had already received education on patients' information protection, but this did not affect their practice of patients' health information protection. Kim [4] showed that both hospital- and school-based education on patients' information protection offered to nursing college students was simplistic or non-specific, and training was conducted uniformly regardless of the ethical index of each student. As noted in a previous study, the content of education for nursing students should be based on their ethical index.

Among the ethical index domains, respect was the important factor in the practice of patients' health information protection in the current study. Respect refers to an attitude that simultaneously values, acknowledges, and cares for the existence of others; others are considered to have the same dignity as oneself. The respect domain of the IEI applies to communication etiquette and the degree of effort employed to protect personal information [18]. In the current study, respect was associated with the practice of patients' health information protection. That is, participants' degree of preventing and protecting other people's private matters against invasion affected their behavior related to the protection of patients' information. Consistent with our findings, previous studies have reported that strengthening basic ethics education can contribute to improving health information protection practices among health professionals $[24,25]$. One possible reason for this can be inferred from nursing education. Although nursing education does not involve separate subjects for ethical education, it is assumed that the overall curriculum emphasizes human respect. However, the IEI domains of temperance, responsibility, and participation are related to nursing students' behavior in hospitals to protect patient information. Because their ethical responsibilities and duties differ from those of nursing professionals, nursing students may have limited opportunities to act appropriately; namely in a manner that does not exceed one's own ability to judge situations appropriately (temperance).

Although the current study identified factors associated with practice of patients' health information protection among nursing students, there are limitations that need to be considered when interpreting our findings. First, the results might reflect healthcare information protection within the participants' limited geographic area and healthcare environment. Second, when the IEI was developed by Kim [18], the index was used after standardization. Although the sum for each IEI domain was used without stand- ardization with the developer's permission, measurement error remains possible.

Nevertheless, this study identified the need to improve educational methods related to nursing students' ethics index. Future research is needed on whether strategies to increase all areas of the ethics index can affect information protection behavior. We further showed that improvement of awareness of patients' health information protection can be related to its practice in nursing students. Therefore, various education programs should be developed, including the development of possible case scenarios, to prevent unethical behavior among nursing students.

\section{CONCLUSION}

Among nursing students, religion, ethics index, and awareness of patients' health information protection were important factors in the practice of patients' health information protection. Nursing students need to be educated to develop awareness of information ethics and to cultivate their ability to act on it. Accordingly, healthcare systems also need to develop practical education programs to improve ethical awareness among students, based on their ethics index. Moreover, future studies should investigate how the ethical index relates to ethical decisionmaking, and which methods could facilitate the improvement of ethical behavior among nursing students.

\section{REFERENCES}

1. Korean Institute for Healthcare Accreditation (KOIHA). Personal information protection guideline for medical institutions. Seoul: KOIHA; 2014 [cited 2019 June 30]. Available from: http://www.koiha.kr/member/kr/board/establish/establish _BoardView.do

2. Ministry of Health and Welfare. A guideline for personal information protection in healthcare institutions. Sejong city: MOHW; 2015 [cited 2019 June 30]. Available from: http://www.mohw.go.kr/react/jb/sjb0406vw.jsp?PAR_ME NU_ID=03\&MENU_ID=030406\&CONT_SEQ=337786

3. KimSY. Nurses' knowledge, awareness, and performance about patients' personal information protection [master's thesis]. Jeonju: Jeonbuk National University; 2012. p. 1-63.

4. Kim CH, Jeong SY, Song YS. Recognition and performance of patient private information protection (PPIP) in nursing students. Journal of Digital Convergence. 2013;11(11):479-490. https://doi.org/10.14400/JDPM.2013.11.11.479

5. Jung KI, Jung HY. A study on the student nurse's perception and performance protecting behavior for the patient medical 
information. The Korean Journal of Health Service Management. 2011;5(4):65-79.

https://doi.org/10.12811/kshsm.2011.5.4.065

6. Bae SJ, Choi YJ. The perception survey for personal health information protection of first aid training courses students Focused of EMT students and nursing students. Journal of Korean Clinical Health Science. 2014;2(1):25-34. https://doi.org/10.15205/kschs.2014.2.1.25

7. Choi SY, Lim DY, Ko IS, Moon IO. Perception and performance about patients' medical information protection in allied health college students. Journal of Korean Academic Society of Nursing Education. 2016;22(1):83-95.

https://doi.org/10.5977/jkasne.2016.22.1.83

8. Ministry of Education. 2011 Curriculum. Seoul; 2011 [cited 2019 June 30]. Available from:

https://www.moe.go.kr/boardCnts/view.do?boardID=141 $\&$ lev $=0 \&$ status $Y N=C \& s=$ moe $\& m=0404 \&$ op Type $=\mathrm{N} \&$ boardS eq $=28167$

9. Cho SH, Kim SS. The delphi analysis to measure the information communication ethics consciousness level of young people. Journal of the Korean Association of Information Education. 2008;12(4):449-457.

10. Cho SH. The development of scale based on TPB to measure the information communication ethics awareness. The Journal of Curriculum and Evaluation. 2012;15(1):291-320. https:// doi.org/10.29221/jce.2012.15.1.291

11. An SH. A study on the level of awareness for patient privacy protection (Focusing on healthcare workers) [master's thesis]. Seoul: Department of Health Policy and Hospital Management Graduate School of Public Health, Korea University; 2011. p. 1-71.

12. Lee MY, Song YS. A study on patients' perception of nurses' behavior in protecting patient privacy. Journal of Korean Academy of Fundamentals of Nursing. 2007;14(2):204-212.

13. Shin AM, Lee IH, Lee KH, Yoon KI. An analysis of the behavior of tertiary care hospital employee in ensuring the confidentiality of patient records. Korean Journal of Hospital Management. 2010;15(2):84-106.

14. Yu M, Kim MO. Neonatal nurses' professional self-concept and behavior to protect patient privacy. Journal of Korean Academic of Nursing Administration. 2012;18(4):424-433. https://doi.org/10.11111/jkana.2012.18.4.424

15. Bae YJ, Lee SY. A study of student nurses' knowledge and awareness about patients' personal information protection. Journal of the Korea Academia-Industrial cooperation Society. 2016;17(1):36-44. https:// doi.org/10.5762/KAIS.2016.17.1.36

16. Jung EY, Jung SJ. A study on perception and practice of protecting the patient medical information in some general hospital employees. The Korean Journal of Health Service Management. 2014;8(4):35-45. https://doi.org/10.12811/kshsm.2014.8.4.035

17. Faul F, Erdfelder E, Buchner A, Lang AG. Statistical power analyses using $G^{*}$ Power 3.1: Tests for correlation and regression analyses. Behavior Research Methods. 2009;41(4): 1149-1160. https://doi.org/10.3758/BRM.41.4.1149

18. Kim KM, Kim SS. Development and validation of the information and communication ethics index of adolescents. The Journal of Curriculum and Evaluation. 2014;17(3):191-221. https://doi.org/10.29221/jce.2014.17.3.191

19. Song YS, Lee MY, Jun YH, Lee YH, Cho JH, Kwon MG, et al. Revision of the measurement tool for patients' health information protection awareness. Healthcare Informatics Research. 2016;22(3):206-216. https://doi.org/10.4258/hir.2016.22.3.206

20. An ES. Study of ethical values and the nature of ethical dilemmas of clinical nurses [master's thesis]. Seoul: Ewha Womans University; 1994. p. 59-65.

21. Lim MH. Effects of moral sensitivity and critical thinking disposition on perceived ethical confidence in nursing students. Journal of the Korea Academia-Industrial cooperation Society. 2016;17(9):610-618. https://doi.org/10.5762/KAIS.2016.17.9.610

22. Jang HC. The religious influence on morality in late Korean society: An analysis of the social survey on "religion and social progress in Korea, 2014". The Korean Journal of Humanities and the Social Sciences. 2015;39(1, 2):175-200.

23. Lee MY, Park YI. A study on the nurse's perception and performance of protecting patient privacy. Journal of Korean Clinical Nursing Research. 2005;11(1):7-20.

24. Jeon YJ. The medical information protection and major issues. Journal of the Korea Society of Computer and Information. 2012;17(12):251-258. https://doi.org/10.9708/jksci/2012.17.12.251

25. Beauchamp TL, Childress JF. Principles of biomedical ethics. 6th ed. Oxford: Oxford University Press; 2009. p. 30. 